\title{
PUBLISHER CORRECTION OPEN Publisher Correction: Quantum spin fluctuations and evolution of electronic structure in cuprates
}

Evgeny A. Stepanov ${ }^{1,2}$, Lars Peters ${ }^{1}$, Igor S. Krivenko ${ }^{3}$, Alexander I. Lichtenstein ${ }^{2,4}$, Mikhail I. Katsnelson ${ }^{1,2}$ and Alexey N. Rubtsov ${ }^{5,6}$ npj Quantum Materials (2018)3:61 ; doi:10.1038/s41535-018-0135-y

Correction to: npj Quantum Materials; https://doi.org/10.1038/ s41535-018-0128-x, Published online 31 October 2018

During the typesetting process of the original version of this Article the nomenclature for the nodal and anti-nodal points was incorrectly given. This has now been corrected in the HTML and PDF versions of the Article.

Open Access This article is licensed under a Creative Commons Attribution 4.0 International License, which permits use, sharing, adaptation, distribution and reproduction in any medium or format, as long as you give appropriate credit to the original author(s) and the source, provide a link to the Creative Commons license, and indicate if changes were made. The images or other third party material in this article are included in the article's Creative Commons license, unless indicated otherwise in a credit line to the material. If material is not included in the article's Creative Commons license and your intended use is not permitted by statutory regulation or exceeds the permitted use, you will need to obtain permission directly from the copyright holder. To view a copy of this license, visit http://creativecommons. org/licenses/by/4.0/.

(c) The Author(s) 2018

Institute for Molecules and Materials, Radboud University, 6525AJ Nijmegen, The Netherlands; ${ }^{2}$ Theoretical Physics and Applied Mathematics Department, Ural Federal

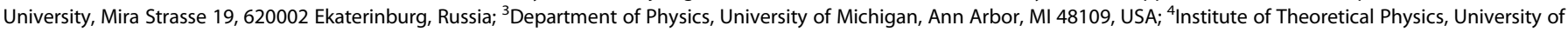
Hamburg, 20355 Hamburg, Germany; ${ }^{5}$ Russian Quantum Center, 143025 Skolkovo, Russia and ${ }^{6}$ Department of Physics, M.V. Lomonosov Moscow State University, 119991 Moscow, Russia

Correspondence: Evgeny A. Stepanov (e.stepanov@science.ru.nl)

Published online: 19 November 2018 